\title{
Glutamate Receptor Subtypes Mediate Excitatory Synaptic Currents of Dopamine Neurons in Midbrain Slices
}

\author{
Giampaolo Mereu, a Erminio Costa, David M. Armstrong, and Stefano Vicini \\ Fidia-Georgetown Institute for the Neurosciences, Georgetown University, Washington, D.C. 20007
}

\begin{abstract}
Although dopamine (DA)-containing neurons participate in a number of important cerebral functions, the physiology of their synaptic connections is poorly understood. By using whole-cell patch-clamp recording in thin slices of rat mesencephalon, we have investigated the biophysical properties of synaptic events and the nature of neurotransmitter(s) and receptors involved in the synaptic input to DA neurons in substantia nigra. The histological and electrophysiological characteristics of these cells were consistent with those described by recent in vivo and in vitro studies, thus allowing their unequivocal identification. Under appropriate experimental conditions, intranigral stimulation produced excitatory synaptic inputs in DA neurons. By voltage-clamp analysis, most of these excitatory postsynaptic currents (EPSCs) had a rise time of about $1.0 \mathrm{msec}$ and a decay phase that could be fit by the sum of two exponential curves so that a fast and a slow component could be distinguished. The slow component was enhanced by glycine, by removing $\mathrm{Mg}^{2+}$ from the bath medium, or by membrane depolarization. Moreover, the slow component was consistently decreased by selective antagonists of NMDA receptors, whereas an antagonist for the non-NMDA receptors abolished the fast component slightly affecting the slow component and reduced peak EPSC amplitude. The results indicate that both NMDA-sensitive and non-NMDA-sensitive glutamate receptors contribute to EPSCs of DA neurons. Therefore, it is suggested that these receptors may play a critical role in the physiology (control of excitability, pacemaker firing, and dendritic DA release) as well as pathology (neuronal death in Parkinson's disease, psychosis, and mechanism of action of drugs of abuse, such as ethanol) related to DA neurons.
\end{abstract}

Mesencephalic dopamine (DA)-containing neurons participate in the complex network of basal ganglia and appear to play an important role in a number of neuronal functions and affective behaviors. For instance, it is well accepted that Parkinson's disease originates from a degenerative process affecting these

\footnotetext{
Received Sept. 21, 1990; revised Nov. 29, 1990; accepted Dec. 11, 1990.

We thank the late $S$. M. Schuetze for the acquisition and curve-fitting computer programs. We also thank R. Brady and R. Scheffeld for the immunohistochemistry and F. H. Travagli for editorial assistance. S.V. is supported by NICDS Program Project Grant PO1 NS 28130-01. D.M.A. is supported by NIH Grants AG 05344 and AG 08206 .

Correspondence should be addressed to Dr. Stefano Vicini, FGIN, Georgetown University, School of Medicine, 3900 Reservoir Road N.W., Washington, DC 20007.

a Permanent address: Department of Experimental Biology, University of Cagliari, 09123 Cagliari, Italy.

Copyright $\odot 1991$ Society for Neuroscience $0270-6474 / 91 / 111359-08 \$ 03.00 / 0$
}

cells (Hornykyewicz, 1966; Marsden, 1990). Furthermore, DAergic projections have been implicated in the etiology of various psychotic disorders (Snyder, 1973; McKenna, 1987), as well as in the mechanism of action of drugs of abuse (Mereu et al., 1988; Hurd et al., 1989). However, in spite of the fact that pharmacology and electrophysiology of DA neurons have been investigated extensively in the last two decades (see Chiodo and Freeman, 1987), several aspects of their membrane properties and of their synaptic connections remain uncertain. Intracellular recordings from slice preparations have shown that these neurons characteristically exhibit a prominent afterhyperpolarization, followed by a very slow depolarization triggering the spontaneous generation of action potentials, which occur fairly regularly and at a slow rate (Llinas et al., 1984; Kita et al., 1986; Chiodo and Freeman, 1987; Grace and Onn, 1989; Harris et al., 1989; Lacey et al., 1989). Such pacemakerlike activity is maintained in dissociated DA neurons and appears to be controlled by at least five potassium and two calcium conductances (Harris et al., 1989; Silva et al., 1990). Previous in vivo and in vitro studies have demonstrated that DA, GABA, high concentrations of glycine, and baclofen (an agonist of the $\mathrm{GABA}_{\mathrm{B}}$ receptor) inhibit the spontaneous activity of DA neurons (Grace and Bunney, 1985; Chiodo and Freeman, 1987; Lacey et al., 1988, 1989; Mercuri et al., 1990). On the other hand, DA neurons are excited in vivo by iontophoretically applied glutamate (Scarnati et al., 1986). However, our goal was to gain information on the synaptic events that regulate DA neuron activity. Indeed, while anatomical and biochemical evidence (see StormMathisen and Ottersen, 1989) indicates that the substantia nigra (SN) does receive corticofugal innervation from glutamate-containing terminals, little is known about the electrophysiology of this input, except that EPSPs (Kang et al., 1989) and orthodromic extracellular spikes can be generated by subthalamic and pedunculopontine nuclei stimulation (Hammond et al., 1983; Scarnati et al., 1986). Moreover, the latter input appears to be suppressed by glutamate antagonists (Scarnati et al., 1986), though the drugs used were not specific for glutamate receptor subtypes.

Therefore, to characterize the synaptic input to DA neurons in the substantia nigra pars compacta (SNC) and to identify the neurotransmitters and receptors involved, we performed lownoise, high-resolution, whole-cell recordings (Hamill et al., 1981) in slices of rat mesencephalon (Edwards et al., 1989).

\section{Materials and Methods}

Slice preparation. Rats, at age 15-21 d, were decapitated, and the brains were rapidly removed under ice-cold Ringer's solution. By using a vibrating microtome, $3-4$ thin $(150-200 \mu \mathrm{m})$ coronal slices were obtained from each brain (Edwards et al., 1989). Slices were studied at room 
Figure 1. Photomicrograph showing an example of recording $(r)$ and stimulating $(s)$ sites. DAergic cell bodies and dendritic process are stained with $\mathrm{TH}$ antisera (see Materials and Methods). Cells positively identified as DAergic by their electrical membrane properties were always found within SNC. $M L$, medial lemniscus. Scale bar, $500 \mu \mathrm{m}$.

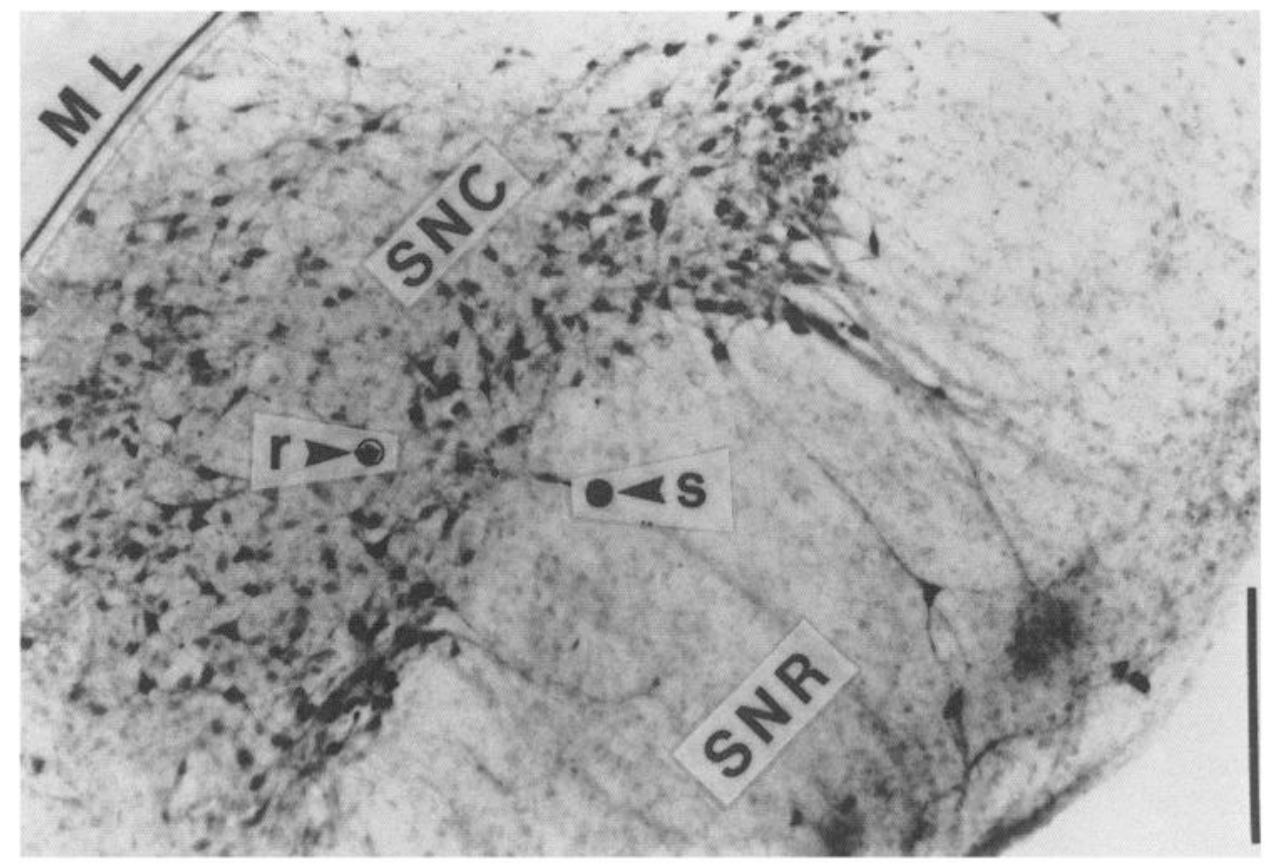

temperature $\left(21-24^{\circ} \mathrm{C}\right)$ on the stage of an upright microscope (Zeiss UEM, GER) equipped with interferential-contrast Nomarski optics.

Solutions and drugs. Ringer's solution contained (in $\mathrm{mm}$ ) $\mathrm{NaCl}(120)$, $\mathrm{KCl}$ (3.1), $\mathrm{Na}_{2} \mathrm{HPO}_{4}$ (1.25), $\mathrm{NaHCO}_{3}$ (26), dextrose (5.0), $\mathrm{MgCl}_{2}(1.0$ ), and $\mathrm{CaCl}_{2}(2.0)$. The solution was maintained at $\mathrm{pH} 7.4$ by bubbling with $5 \% \mathrm{CO}_{2}, 95 \% \mathrm{O}_{2}$. Patch pipettes were filled with (in $\mathrm{mm}$ ) $\mathrm{K}$-gluconate (145), $\mathrm{MgCl}_{2}(1.0)$, EGTA (5.0), ATP (2.0), and HEPES-KOH (10) to $\mathrm{pH}$ 7.2. $\mathrm{CsCl}(145 \mathrm{~mm})$ was substituted for K-gluconate in the current to voltage-curve experiments. Drugs were added to the Ringer's solution, which was perfused at a rate of $5 \mathrm{ml} / \mathrm{min}$. All drugs were kept in stock solution in the dark. Glycine (Sigma, St. Louis, MO) was dissolved in the Ringer's solution; 7-chlorokynurenic acid (7-Cl-KA; Tocris, Buckhurst Hill, UK), in dimethyl sulfoxide (final dilution, $\geq 0.1 \%$ ); picrotoxin (Sigma), in hot water; mecamylamine (Sigma) and DL-2amino-5-phosphonovalerate (APV; Tocris), in water; and 6-cyano-7dinitroquinoxaline-2,3-dione (CNQX; Tocris), in $20 \mathrm{~mm}$ Tris.

Electrophysiology. Low-resistance (3-5 M $\Omega$ ) patch electrodes were pulled (Narishige, PP-83, Tokyo, Japan) from borosilicate glass capillaries of $1.8 \mathrm{~mm}$ outer diameter (Drummond, Broomall, PA). No fire polishing or Sylgard coating was used. Series resistance (10 M $\Omega)$, in whole cell configuration, was compensated and monitored for constancy throughout the experiment. Current and voltage signals at the headstage of the patch-clamp amplifier (List EPC-7, Darmstad, GER) were filtered at $2.0 \mathrm{kHz}$ (8-pole low-pass Bessel LP902, Frequency Devices, Haverhill, MA) and continuously displayed on an oscilloscope. Events of interest were captured on VCR magnetic tape (VR 10-A, Instrutech Corp., Elmont, NY) for off-line analysis (LSI 11/73 computer, Indec System, Sunny Vale, CA) at a sampling rate of $5 \mathrm{kHz}$. The amplitudes and decay time constants of synaptically evoked currents were determined by finding the values that gave the best (least-squares) fit to single or double exponential equation of the form

$$
I_{T}(t)=I_{f} \cdot \exp \left(-t / \tau_{f}\right)+I_{s} \cdot \exp \left(-t / \tau_{s}\right)
$$

where $I_{T}$ is the EPSC total amplitude, $t$ is time, $I_{f}$ and $I_{s}$ are the peak amplitudes, and $\tau_{f}$ and $\tau_{s}$ are the decay time constants of fast $(f)$ and slow $(s)$ components, respectively. The procedure, which uses a Simplex algorithm to fit the data to the equations, was entirely automated. The procedure also estimated the percent contribution of $I_{s}$ to $I_{T}$ as

$$
\% I_{s}=100 \cdot I_{s} / I_{T} \text {. }
$$

Stimulation. Stimuli (square-wave electric pulses of $100-300-\mu \mathrm{A}$ intensity, 50- $\mu$ sec duration, and $0.2-\mathrm{Hz}$ frequency) were delivered into the SN pars reticulata (SNR) through concentric electrodes (D. Kopf, Tujunga, CA) positioned $250-750 \mu \mathrm{m}$ distally from the recorded cell, along a direction approximately perpendicular to the medial lemniscus (Fig. 1)

Immunohistochemistry. For intracellular staining, the tip of recording pipette was filled with Lucifer yellow CH (Sigma, $1.0 \mathrm{mg} / \mathrm{ml}$ in the recording solution). The dye was ejected by pulse $(200 \mathrm{msec}, 0.5 \mathrm{~Hz})$ of negative current $(1.0 \mathrm{nA})$ for $5 \mathrm{~min}$. For tyrosine hydroxylase $(\mathrm{TH})$ immunoreactivity, slices were placed in fixative $(4 \%$ paraformaldehyde in $0.1 \mathrm{M}$ phosphate buffer) and then processed for immunocytochemistry using an avidin-biotin immunolabeling procedure (Hsu and Raine, 1981) and a polyclonal antibody (Eugene Tech. Int., Allendale, NJ) against TH.

\section{Results}

\section{Electrophysiological and immunohistological identification}

Nigral neurons were localized under microscopic vision (total magnification, $500 \times$ ), and those within the SNC (Fig. 1) were identified as DAergic versus non-DAergic on the basis of their respective in vitro electrophysiological properties (Llinas et al., 1984; Kita et al., 1986; Chiodo and Freeman, 1987; Grace and Onn, 1989; Harris et al., 1989; Lacey et al., 1989; Silva et al., 1990). Briefly, it was observed that putative DAergic neurons very often displayed spontaneous activity at a constant rate of $0.5-3.0 \mathrm{~Hz}$. This activity became apparent upon suction to obtain the cell-attached gigaseal (>10 G $\Omega$ ) configuration (Hamill et al., 1981), and it was maintained, after disruption of patch membrane, in whole-cell current-clamp mode (Fig. $2 A$ ). Indeed, at their resting potential of $-58 \pm 2.5 \mathrm{mV}$ (mean \pm SEM), these cells exhibited a characteristic pacemaker firing pattern consisting of isolated, wide action potentials of $2.5-5.0 \mathrm{msec}$ duration (measured at the threshold level of $-48 \pm 4 \mathrm{mV}$ ) and spike amplitudes of 70-80 $\mathrm{mV}$ from threshold, which were followed by a pronounced and long afterhyperpolarization. Application of DA $(5 \mu \mathrm{M})$ resulted in a rapid termination of activity associated with membrane hyperpolarization (Fig. $2 A$ ). Under hyperpolarizing current pulses, the membrane voltage deflections showed inward (anomalous) rectification (not shown).

On the contrary, non-DA cells were rarely spontaneously active at their resting potentials of $-64 \pm 4.2 \mathrm{mV}$. However, after 


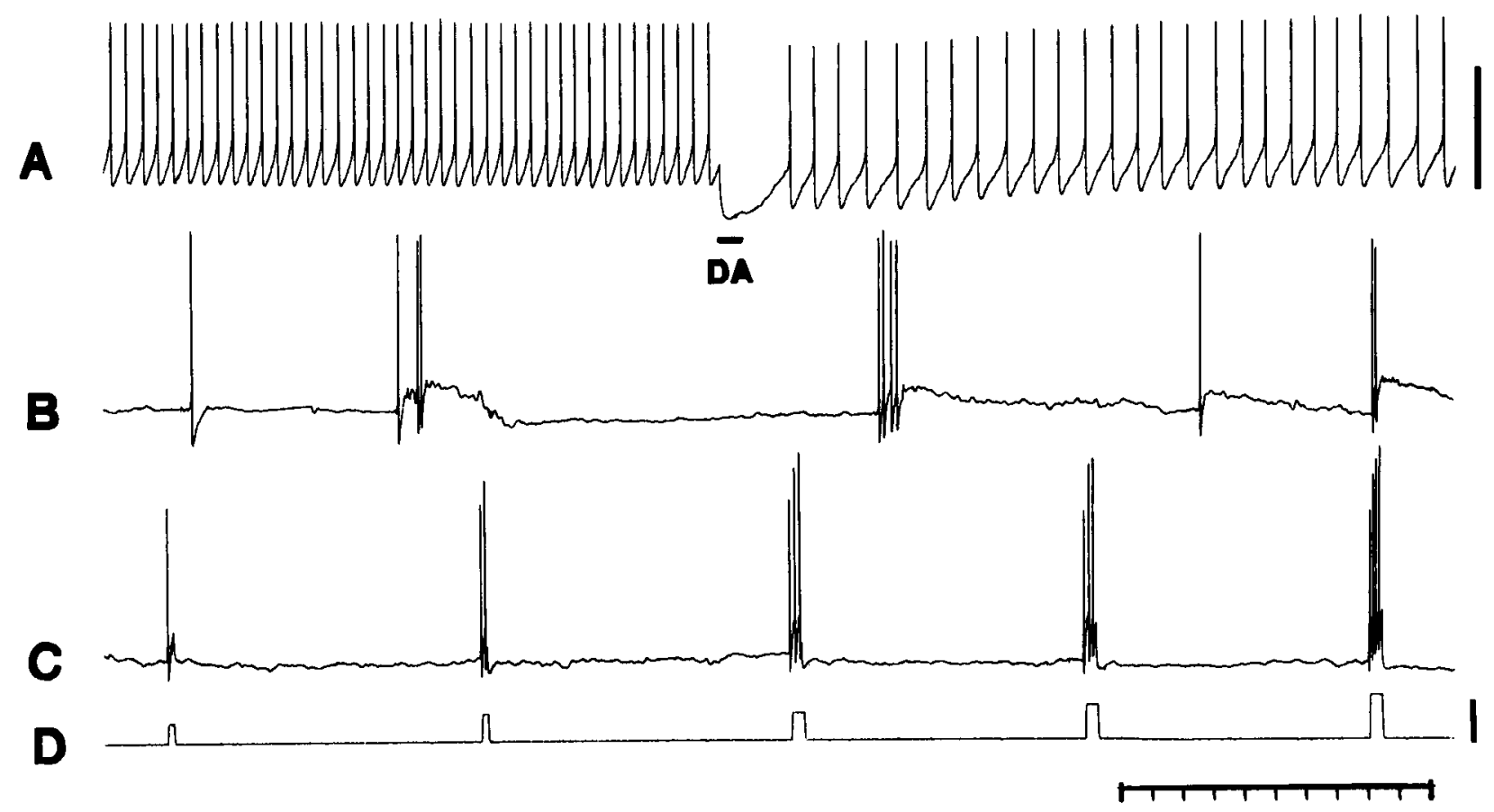

Figure 2. Whole-cell current-clamp recording from DA and non-DA neurons with electrodes filled with $\mathrm{K}$-gluconate as major current carrier (see Materials and Methods). $A$, This DA neuron was spontaneously active, had resting potential of $-56 \mathrm{mV}$, and exhibited the characteristically slow pacemaker firing $(2 \mathrm{~Hz}$ ) with wide action potentials (about $3.5 \mathrm{msec}$ duration in this neuron) followed by long afterhyperpolarization. Application of DA $(5 \mu \mathrm{M})$ resulted in the termination of spiking activity and membrane hyperpolarization. $B$, Example of a non-DA neuron (quiescent at its resting potential of $-62 \mathrm{mV})$ depolarized to the threshold voltage $(-50 \mathrm{mV})$ by current injection. Action potentials $(1.8 \mathrm{msec})$ occurred singularly or in short bursts. $C$, In the same cell as in $B$, a similar firing pattern was elicited by depolarizing pulses $(D ; 100-200 \mathrm{pA}, 400 \mathrm{msec})$ from resting potential. Calibration: $50 \mathrm{mV}, 10 \mathrm{sec}$ for $A-C ; 200 \mathrm{pA}, 10 \mathrm{sec}$ for $D$.

depolarization to the threshold voltage $(-51 \pm 4.8 \mathrm{mV})$, action potentials $(\leq 2.2 \mathrm{msec})$ occurred singularly or packed in short bursts (Fig. $2 B$ ). Similar irregular activity was elicited in these non-DA cells by depolarizing pulses (100-200 pA), as shown in Figure $2 C$. The spontaneous or evoked activity of non-DA neurons was relatively insensitive to DA. Moreover, these neurons did not display inward rectification.

With the use of CsCl-filled electrodes, we measured the membrane input resistance to be $200-700 \mathrm{M} \Omega$ in both cell populations, a value much higher than that reported by conventional intracellular recording in slices (Grace and Onn, 1989), but comparable to that observed by Silva et al. (1990) using whole-cell recording of dissociated nigral DA neurons. The Lucifer yellow dye was injected into 12 neurons, positively identified as DAergic by their electrical properties. Cell bodies of DA neurons were of medium-size diameter (20-30 $\mu \mathrm{m})$, had fusiform or multipolar shape, and generated two to five major dendritic processes extending medially or laterally within SNC or ventrally to SNR. Morphology of DA neurons is not shown because it was consistent with that already described in detail by Grace and Onn (1989) and Juraska et al. (1977).

\section{Synaptic currents in $S N$ neurons}

Stimuli were delivered at low frequency $(0.2 \mathrm{~Hz})$ in the edge between SNC and SNR (Fig. 1), where the dense dendritic projections of DA neurons are located (Juraska et al., 1977). In DA neurons, voltage clamped at $-50 \mathrm{mV}$, stimulation elicited pure excitatory postsynaptic currents (EPSCs) in $79 \%(26 / 33)$ of neurons in the presence of $50 \mu \mathrm{M}$ picrotoxin (an antagonist of the $\mathrm{GABA}_{\mathrm{A}}$ receptor), as well as in $56 \%(18 / 32)$ of neurons in the absence of the toxin. The remaining DA neurons showed either no response, inhibitory postsynaptic currents (IPSCs), or mixed EPSCs-IPSCs. the majority of neurons (13/20) with membrane properties corresponding to those of non-DA cells located within the SNC also showed EPSCs. In a number of DA $(n=16)$ and non-DA $(n=9)$ neurons, spontaneous miniature EPSCs were present. However, for the purpose of the present study, we analyzed only pure EPSCs generated in identified DA neurons. Unless otherwise stated, evoked EPSCs were studied with perfusion solution containing glycine (1.0 $\mu \mathrm{M}$; Johnson and Ascher, 1987), $\mathrm{Mg}^{2+}$ (1.0 mM; Mayer et al., 1984; Nowak et al., 1984), and picrotoxin $(50 \mu \mathrm{M})$.

At holding potential (HP) close to the membrane resting potential ( -60 to $-50 \mathrm{mV}$ ), evoked EPSCs had peak amplitudes ranging from 10 to $300 \mathrm{pA}$, depending on the stimulus strength. At fixed stimulus intensity, amplitudes fluctuated between discrete values (Fig. $3 A$ ), as would be expected for either quantal release or variability in the number of presynaptic inputs activated. Most EPSC rise times were quite fast (about $1.0 \mathrm{msec}$ ), and we rejected those with a rise time $>3.0 \mathrm{msec}$ because, as suggested by Hestrin et al. (1990), they might reflect a poor spatial voltage clamp of the thin and extended distal dendrites of DA neurons (Juraska et al., 1977). In the experimental condition chosen, the decay phase could be fit by either a single exponential curve or by the sum of two exponentials. In 126 EPSCs recorded from five neurons, the decay phase had a single component with a time constant, $\tau$, of $4.2 \pm 0.61 \mathrm{msec}$, with a range of 2.1-8.3 msec. However, 935 EPSCs from 26 other cells were fit by two exponentials (Fig. $3 B$ ). The time constant of the initial fast component, $\tau_{f}$, was $4.4 \pm 0.32 \mathrm{msec}$, with a range of 

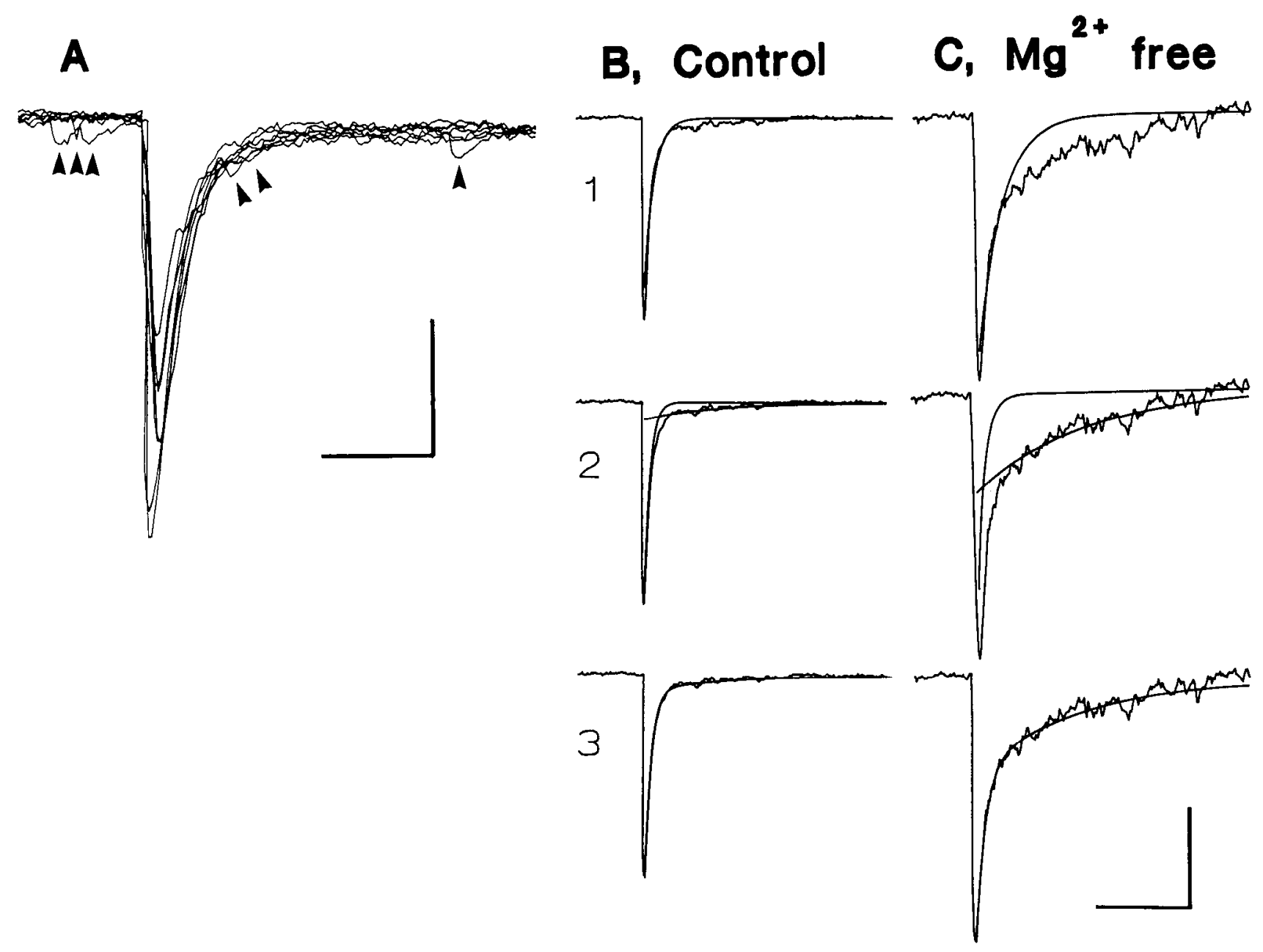

Figure 3. Properties of evoked EPSCs in DA cells. A, Seven evoked EPSCs have been superimposed to observe the fluctuation of amplitudes at a fixed stimulus intensity $(150 \mu \mathrm{A})$. Note the occurrence of spontaneous miniature EPSCs (arrowheads). $B$, Fitting analysis of EPSC decay phases in control condition. The matching degree of one (superimposed) exponential curve (1), two distinct exponential curves (2), and the sum of them (3) is illustrated. $C$, Same analysis after omission of $\mathrm{Mg}^{2+}$ ions from Ringer's solution. Both control and $\mathrm{Mg}^{2+}$-free EPSCs are the averages of five distinct events. In the presence of $\mathrm{Mg}^{2+}(1.0 \mathrm{mM})$, the slow exponential component, $I_{s}$, of this cell was $5 \%$ of the total current amplitude. It increased to $35 \%$ in the absence of $\mathrm{Mg}^{2+}$. Calibration: $50 \mathrm{pA}, 10 \mathrm{msec}$ for $A ; 50 \mathrm{pA}, 20 \mathrm{msec}$ for $B$.

2.5-6.8 msec, whereas that of the slow component, $\tau_{s}$, was 39 $\pm 3.1 \mathrm{msec}$, with a range of $14-65 \mathrm{msec}$ (see Table 1). The contribution of the slow component, $I_{s}$, to the total peak amplitude, $I_{T}$, was $16 \pm 4.2 \%$, with a range of $0.5-38 \%$. The slow component of the synaptic current decay phase was enhanced cither by removing $\mathrm{Mg}^{3+}$ (Fig. $3 C$ ) or by membrane depolarization to values more positive than $-30 \mathrm{mV}$ (Fig. $4 A, B$ ). Conversely, in the presence of $1.0 \mathrm{~mm} \mathrm{Mg}^{2+}$, the slow component was reduced or abolished by membrane hyperpolarization greater than $-60 \mathrm{mV}$ (Fig. $4 A, B$ ) or by omitting glycine from the perfusion solution, as described by Forsythe and Westbrook (1988). The voltage dependence of $I_{T}$ and $I_{s}$ amplitudes is shown in Figure $4 B$. While the $I_{T} / V$ relation was linear, with the exclusion of a notch at $-60 \mathrm{mV}$, the relation between voltage and $I_{s}$ was J-shaped, with a region of a negative slope between -70 and $-30 \mathrm{mV}$. The reversal potential was close to $0 \mathrm{mV}$ for both currents.

\section{Pharmacology of EPSCs}

The biophysical properties of EPSCs generated in SNC neurons were similar to those mediated by glutamate receptor activation in other neuronal populations (Forsythe and Westbrook, 1988), most notably in CA1 hippocampal neurons (Hestrin et al., 1990). However, with respect to these studies, EPSC kinetics of DA neurons appear to be faster. A possible cholinergic contribution was considered unlikely because application of mecamylamine $(25 \mu \mathrm{M})$, a nicotinic $\mathrm{ACh}$ receptor antagonist, failed to affect EPSCs from DA neurons ( $n=3$; not shown), and also because the EPSCs mediated by muscarinic receptors have been reported (Cole and Nicoll, 1983) to be much slower. Therefore to determine whether EPSCs in DA neurons were actually mediated by glutamate and, if so, to characterize the subtypes of receptor involved, we studied EPSC kinetics in the presence of different and specific glutamate receptor antagonists. Indeed, it is known that, though both NMDA-sensitive and kainate- or quisqualatesensitive (i.e., non-NMDA) glutamate receptors are activated during excitatory synaptic input, the slow (NMDA) and fast (non-NMDA) components of EPSCs are pharmacologically separable (Forsythe and Westbrook, 1988; Hestrin et al., 1990).

As shown in Figure 5 and Table 1, APV $(50 \mu \mathrm{M})$, an NMDA receptor antagonist (Monaghan et al., 1989), reduced the peakamplitude $I_{T}$ of EPSCs by $40 \%$, mainly by affecting the percent 


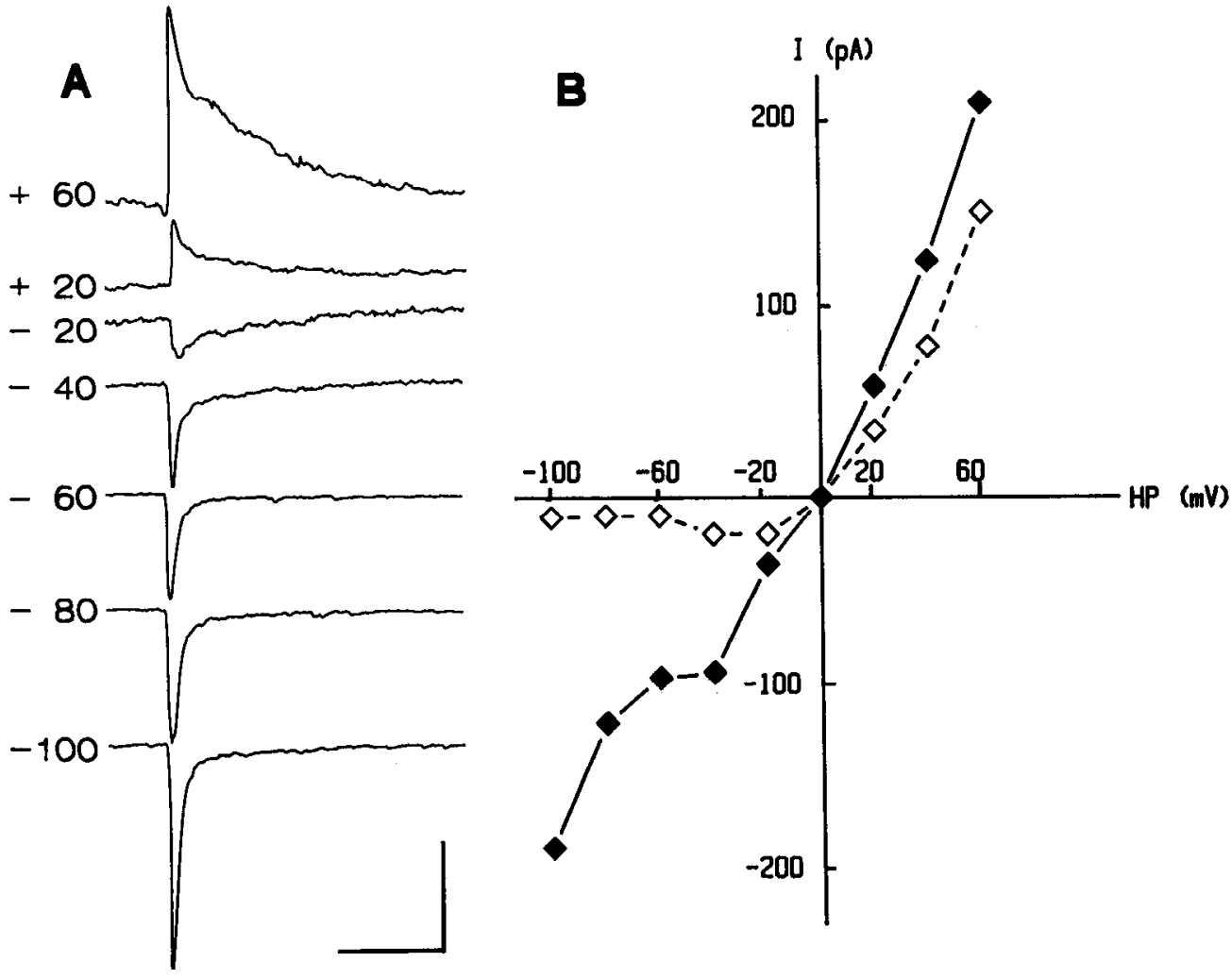

Figure 4. Voltage dependence of EPSCs in DA neurons. $A$, Evoked EPSCs recorded at different HPs (mV) as indicated. Each trace is the average of 5-10 events. Calibration, $50 \mathrm{pA}, 20$ msec. $B$, Current versus voltage relation of the EPSC averages, shown in $A$, for $I_{T}(\diamond)$ and $I_{s}(\diamond)$. contribution of $I_{s}$ to $I_{T}$, which was reduced by $53 \%$. Conversely, the non-NMDA receptor antagonist CNQX (10 $\mu \mathrm{M}$; Forsythe and Westbrook, 1988; Hestrin et al., 1990), completely eliminated the fast component; as a consequence, $I_{T}$ was reduced to $15 \%$ of baseline and became equal to $I_{s}$.

A concentration of $50 \mu \mathrm{M}$ of 7-Cl-KA preferentially antagonizes NMDA-sensitive receptors through the blockade of their coupled glycine-sensitive allosteric modulatory site (Kemp et al., 1988), with some antagonistic action also on the non-NMDA receptors, however. When $50 \mu \mathrm{M} 7-\mathrm{Cl}-\mathrm{KA}$ was added in the perfusion solution, both $I_{T}$ and the percentage contribution of $I_{s}$ to $I_{T}$ were inhibited by approximately $50 \%$ and $80 \%$ of control values, respectively. After removal of 7-Cl-KA from the perfusion solution, complete recovery of $I_{T}$ occurred in about 10 $\min$. However, in the case of neurons $(n=6)$ in which the percentage contribution of $I_{s}$ to $I_{T}$ was appreciable $(\geq 5 \%)$ before 7-Cl-KA treatment, $I_{s}$ component gradually reappeared in about 5-8 min of washout. Coapplication of CNQX $(10 \mu \mathrm{M})$ and
7-Cl-KA (50 $\mu \mathrm{M})$, or CNQX perfusion soon after 7-Cl-KA discontinuation, completely abolished EPSCs (not shown). In five cells, perfusion with either APV $(10 \mu \mathrm{M})$ or $7-\mathrm{Cl}-\mathrm{KA}(50 \mu \mathrm{M})$ was associated with a long-lasting outward current of up to 400 $\mathrm{pA}$ and a decrease in membrane conductance. A comparable effect (not shown) was also produced $(n=3)$ by $1.0 \mu \mathrm{M} 7-\mathrm{Cl}$ KA. Figure 6 illustrates a case of 7-Cl-KA $(50 \mu \mathrm{M})$ application.

\section{Effect of drugs on EPSC kinetics}

As stated, under control conditions, the rise time of EPSCs ranged from 0.8 to $1.5 \mathrm{msec}$, while the fast $\left(\tau_{f}\right)$ and slow $\left(\tau_{s}\right)$ time constant decays were 4.4 and $39 \mathrm{mscc}$, respectively. As reported in Table 1, drug application failed to affect time constant decays significantly. It should be observed, however, that after CNQX, $\tau_{f}$ was undetectable while the rise time was enhanced two to three times (Fig. 5). Rise time was unchanged by APV or 7-Cl-KA (Fig. 5).

\begin{tabular}{lcccccc}
\hline Table 1. & Pharmacology of EPSCs in DA cells & & & \\
Drugs & $(n)$ & $I_{T}(\mathrm{pA})$ & $I_{s}(\mathrm{pA})$ & Percent $I_{s}$ & $\tau_{f}$ (msec) & $\tau_{s}(\mathrm{msec})$ \\
\hline Control & $(26)$ & $95 \pm 8.7$ & $15 \pm 3.3$ & $16 \pm 4.2$ & $4.4 \pm 0.32$ & $39 \pm 3.1$ \\
APV & $(10)$ & $56 \pm 6.2$ & $4.8 \pm 0.44$ & $8.6 \pm 2.3$ & $5.4 \pm 0.81$ & $38 \pm 2.2$ \\
CNQX & $(8)$ & $10.5 \pm 0.42$ & $10.5 \pm 0.42$ & $100 \pm 20$ & $\mathrm{ND}$ & $29 \pm 4.3$ \\
7-Cl-KA & $(9)$ & $53 \pm 4.5$ & $1.5 \pm 0.23$ & $2.8 \pm 0.35$ & $4.6 \pm 0.52$ & $45 \pm 5.5$
\end{tabular}

Each value represents a mean \pm SEM obtained from the reported number, $(n)$, of cells. From each cell under study, a minimum of 20 EPSCs were sampled during control period and drug application. Because control values were homogeneous, they have been pooled. In the case of cells tested with various agents, a period of washing of at least 15 min was observed. Series resistance was monitored for constancy during this period. The increase in the percent contribution of $I_{s}$ to $I_{T}$ (percent $I_{s}$ ) in the presence of CNQX was due to the disappearance of the $I_{f}$. Drug concentrations were as in Figure 5. ND, not detectable. 

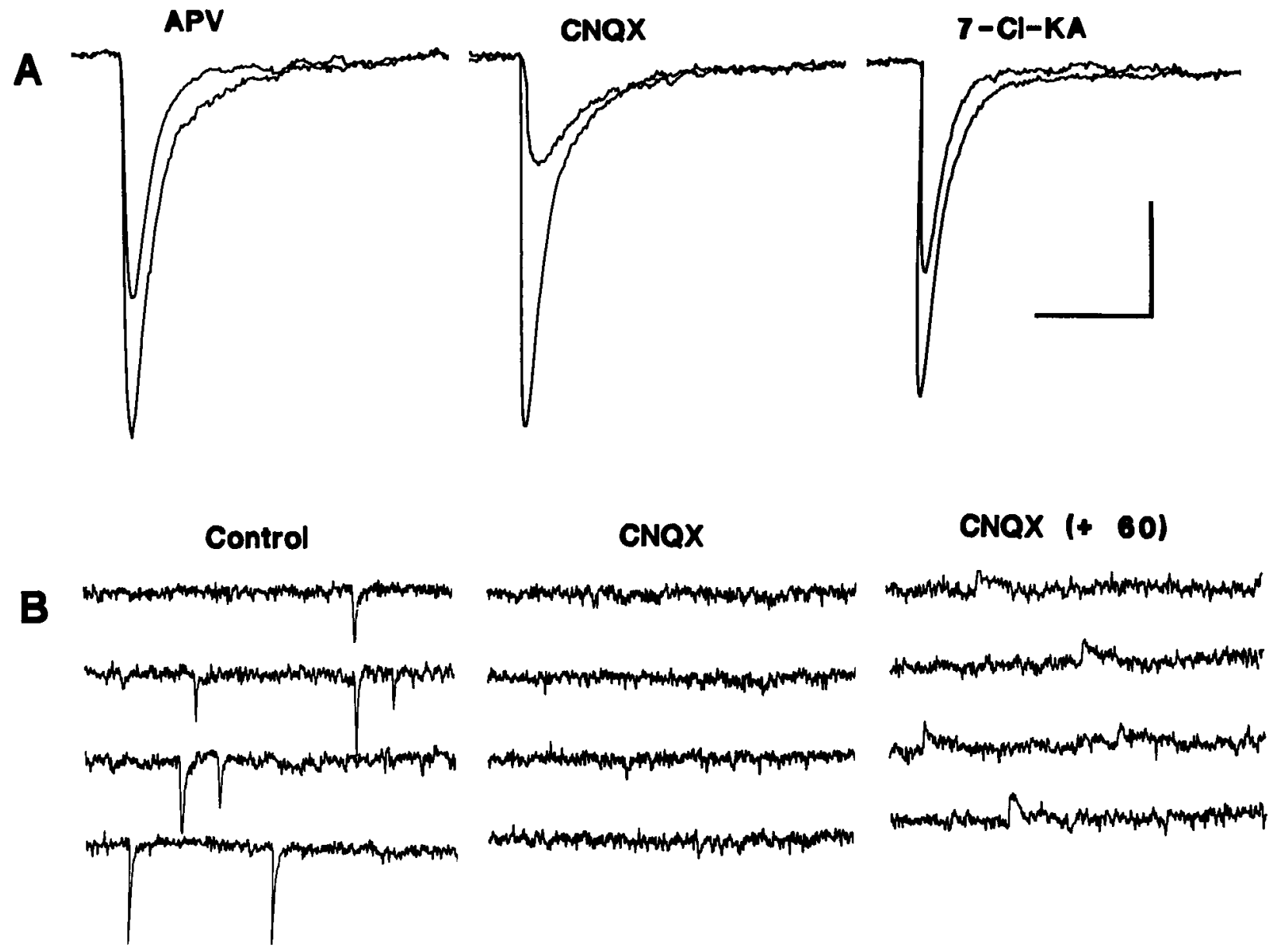

Figure 5. Pharmacology of EPSCs and miniature EPSCs. A, Representative traces showing the modification produced by various glutamate receptor antagonists, such as APV $(50 \mu \mathrm{M})$, CNQX $(10 \mu \mathrm{M})$, and 7-Cl-KA $(50 \mu \mathrm{M})$, on the amplitude and kinetics of EPSCs. Each trace is the average of five distinct events sampled during control period (large EPSC) and drug application (smaller superimposed traces) recorded at resting potential (-50 $\mathrm{mV}) . B$, Example of spontaneous miniature EPSCs occurring at resting potential ( $-55 \mathrm{mV})$, in control condition, after their suppression by CNQX $(10 \mu \mathrm{M})$, and their partial recovery upon membrane depolarization at $+60 \mathrm{mV}$. Calibration: $50 \mathrm{pA}, 20 \mathrm{msec}$ for $A ; 25 \mathrm{pA}, 40 \mathrm{msec}$ for $B$.

\section{Miniature EPSCs}

In a number ( $n=16$ ) of DA neurons, we observed spontaneous miniature EPSCs of $5-40$ pA (Figs. $3 A, 5 B$ ). At resting potential $(-55 \mathrm{mV})$, they were completely eliminated by application of CNQX (10 $\mu \mathrm{M}$; Fig. $5 B$ ), but not by APV ( $50 \mu \mathrm{M}$; not shown). However, upon membrane depolarization to HPs of +30 to

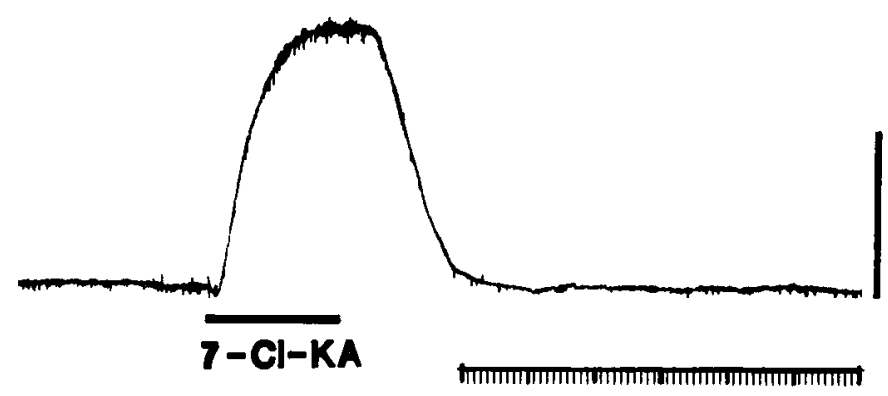

Figure 6. Record of the outward current produced by the application of $7-\mathrm{Cl}-\mathrm{KA}(50 \mu \mathrm{M})$ for $25 \mathrm{sec}$ in the bath solution, as indicated by the bar. Cell membrane potential was held at $-50 \mathrm{mV}$. Intracellular solution contained $\mathrm{CsCl}$ ( $145 \mathrm{~mm}$; see Materials and Methods). Calibration, 200 pA, $1 \mathrm{~min}$.
$+60 \mathrm{mV}$, slow miniature EPSCs were still observed in the presence of CNQX (Fig. 5B).

\section{Discussion}

Glutamate is the most abundant excitatory neurotransmitter in the CNS (see Monaghan et al., 1989; Storm-Mathisen and Ottersen, 1989). By activating specific ionotropic receptor subtypes, glutamate controls ncuronal cxcitability and mediates synaptic plasticity (Monaghan et al., 1989). Moreover, a persistent and paroxysmal stimulation of glutamate receptors causes neuronal excitotoxicity (Choi, 1988; Manev et al., 1990). It has been thought that local nigral circuits and nigro-striatonigral loops were regulated mainly by neurotransmitters, such as DA, GABA, and ACh (Grace and Bunney, 1985; Chiodo and Freeman, 1987; Lacey et al., 1988, 1989). Our results now provide conclusive evidence that SNC-DA neurons in the rat receive a glutamatergic excitatory input that can be activated by intranigral stimulation. The midbrain coronal thin-slice preparation does not allow determination of the origin of these excitatory afferents. However, on the basis of previous studies, we can hypothesize that they arise from subthalamic (Hammond et al., 1983) and pedunculopontine (Scarnati et al., 1986) nuclei, as well as from cortex (Storm-Mathisen and Ottersen, 1989), 
and perhaps also from excitatory interneurons located within the confines of the slices.

The biophysical and pharmacological properties of evoked EPSCs in DA neurons of SNC indicate that both NMDA and non-NMDA receptors are involved. However, because the $I / V$ relation of total EPSC peak amplitudes of DA neurons was not linear in the region of negative voltages (Fig. $3 B$ ), where the $\mathrm{Mg}^{2+}$ blockade of NMDA receptor channels is more effective (Mayer et al., 1984; Nowak et al., 1984; Hestrin et al., 1990), and because both APV and 7-Cl-KA consistently reduced $I_{T}$, one can surmise a faster onset of the NMDA component of synaptic current amplitude in SNC-DA neurons than in pyramidal neurons of hippocampus (Hestrin et al., 1990). Although spontaneous miniature EPSCs were mainly CNQX sensitive, the presence of slow miniature EPSCs at positive potentials indicates a role for both NMDA and non-NMDA receptors in their generation. Moreover, a steady outward current was elicited in some SNC-DA neurons by APV as well as by either low $(1.0 \mu \mathrm{M})$ or high $(50 \mu \mathrm{M})$ concentrations of $7-\mathrm{Cl}-\mathrm{KA}$, indicating that, as in the hippocampus (Sah et al., 1989), NMDA-selective glutamate receptors might be tonically activated. Because it has been inferred that this tonic activation could be present also in vivo (Errington et al., 1987), it is likely that it is influenced not only by "ambient" glutamate (Sah et al., 1989) active in the synaptic cleft, but also by the positive modulation of NMDA receptors by the endogenous glycine (Johnson and Ascher, 1987) present in the interstitial fluid of SNC. Such a possibility is consistent with the different mechanism of action exerted by APV and 7-Cl-KA in inhibiting the $I_{T}$ and $I_{s}$ of EPSCs. Indeed, as shown in Table 1 , both drugs reduce $I_{T}$ by a similar extent, whereas $I_{s}$ is inhibited about $65 \%$ and $90 \%$ by APV and $7-\mathrm{Cl}-$ $\mathrm{KA}$, respectively. These observations indicate that, while APV isosterically antagonizes the action of glutamate on NMDAselective glutamate receptors (Monaghan et al., 1989), 7-Cl-KA produces its antagonistic action through the blockade of the binding site of glycine located on the glutamate receptor domain (Kemp et al., 1988; Costa, 1989).

Whatever the role played by ambient glycine in regulating the slow component of EPSCs, our finding of an excitatory, NMDAand non-NMDA-mediated, input to SNC-DA neurons might have a number of relevant implications, for instance, (1) the excitability of DA neurons may be controlled, in part, by phasic (i.e., synaptic; Hammond et al., 1983; Scarnati et al., 1986; Kang et al., 1989) as well as tonic (Sah et al., 1989) activation of glutamate receptors. (2) As in lamprey spinal cord neurons (Wallen and Grillner, 1987), the tetrodotoxin-insensitive oscillations in membrane potential of DA neurons (Kita et al., 1986; Grace and Onn, 1989; Harris et al., 1989) could be due to $\mathrm{Ca}^{2+}$ and other voltage-dependent conductances that are finely tuned by voltage-sensitive NMDA receptor-operated channels. (3) NMDA receptor-activated current appears to be responsible for $\mathrm{Ca}^{2+}$ dependent dendritic release of DA (Cheramy et al., 1981; Llinas et al., 1984; Araneda and Bustos, 1989). (4) A persistent and paroxysmal activation of NMDA receptors might result in excitotoxicity (Choi, 1988; Manev et al., 1990). Thus, it is conceivable that the glutamatergic innervation of SNC might be responsible, at least in part, for the death of DA neurons that occurs with age (Marsden, 1990) and in Parkinson's disease. This possibility suggests novel strategies in search for Parkinson's disease etiology, diagnosis, and therapy. (5) Finally, because it has been demonstrated (Lovinger et al., 1989) that ethanol inhibits NMDA-activated currents in cultured hippo- campal neurons, it is possible that the reduction of DAergic firing produced by local application of ethanol (Mereu et al., 1988 ) is due to a similar mechanism.

\section{References}

Araneda R, Bustos G (1989) Modulation of dendritic release of dopamine by $N$-methyl-D-aspartate receptors in rat substantia nigra. J Neurochem 52:962-970.

Cheramy A, Leviel V, Glowinski J (1981) Dendritic release of dopamine in the substantia nigra. Nature 245:123-125.

Chiodo LA, Freeman AS (1987) The neurophysiology of dopamine systems. Detroit: Lake Shore.

Choi DW (1988) Glutamate neurotoxicity and disease of the nervous system. Neuron 1:623-633.

Cole AE, Nicoll RA (1983) Acetylcholine mediates a slow synaptic potential in hippocampal pyramidal cells. Science 221:1299-1301.

Costa E (1989) Allosteric modulatory center of transmitter amino acid. Neuropsychopharmacology 2:167-174.

Edwards FA, Konnerth A, Sakmann B, Takahashi T (1989) A thin slice preparation for patch clamp recordings from neurones of mammalian central nervous system. Pfluegers Arch 414:600-612.

Errington ML, Lynch MA, Bliss TVP (1987) Long-term potentiation in the dentate gyrus: induction and increased glutamate release are blocked by $\mathrm{D}(-)$ amino-phosphonovalerate. Neuroscience 20:278-284.

Forsythe ID, Westbrook GL (1988) Slow excitatory postsynaptic currents mediated by $N$-methyl-D-aspartate receptors on cultured mouse central neurones. J Physiol (Lond) 396:515-533.

Grace AA, Bunney BS (1985) Dopamine. In: Neurotransmitter action in the vertebrate nervous system (Rogawski MA, Barker JL, eds), pp 285-319. New York: Plenum.

Grace AA, Onn SP (1989) Morphology and electrophysiological properties of immunocytochemically identified rat dopamine neurons recorded in vitro. J Neurosci 9:3463-3481.

Hamill OP, Marty A, Neher E, Sakmann B, Sigworth FJ (1981) Improved patch-clamp techniques for high resolution current recording from cells and cell-free membrane patches. Pfluegers Arch 391:85100.

Hammond C, Shibazaki T, Rouzaire-Dubois B (1983) Branched output neurons of the rat subthalamic nucleus: electrophysiological study of the synaptic effect of identified cells in the main target nuclei, the ento-peduncular nucleus and the substantia nigra. Neuroscience 9: $511-520$

Harris NC, Webb C, Greenfield SA (1989) A possible pacemaker mechanism in pars compacta neurons of the guinea pig substantia nigra revealed by various ion channel blocking agents. Neuroscience 31:355-362.

Hestrin S, Nicoll RA, Perkel DJ, Shah P (1990) Analysis of excitatory synaptic action in pyramidal cells using whole-cell recording from rat hippocampal slice. J Physiol (Lond) 422:203-225.

Hornykyewicz $O$ (1966) Dopamine (3-hydroxytyramine) and brain function. Pharmacol Rev 18:925-964.

Hsu SM, Raine L (1981) Protein A, avidin, and biotin in immunohistochemistry. J Histochem Cytochem 29:1349-1353.

Hurd YL, Weiss F, Koob GF, And NE, Ungersted U (1989) Cocaine reinforcement and extracellular dopamine overflow in rat nucleus accumbens: an in vivo microdialysis study. Brain Res 498:199-203.

Johnson JW, Ascher P (1987) Glycine potentiates the NMDA response in cultured mouse brain neurones. Nature 325:529-531.

Juraska JM, Wilson CJ, Groves PM (1977) The substantia nigra of the rat: a Golgi study. J Comp Neurol 172:585-600.

Kang Y, Kubota Y, Kitai ST (1989) Synaptic action on substantia nigra compacta neurons by subthalamic inputs studied by a spike trigger averaging method. Soc Neurosci Abstr 15:900.

Kemp JA, Foster AC, Leeson PD, Priestley T, Tridgett R, Iversen LL, Woodruf GN (1988) 7-Chlorokynurenic acid is a selective antagonist at the glycine modulatory site of the $N$-methyl-D-aspartate receptor complex. Proc Natl Acad Sci USA 85:6547-6550.

Kita T, Kita H, Kitai ST (1986) Electrical membranes properties of the rat substantia nigra neurones in an in vitro preparation. Brain Res 372:21-30.

Lacey MG, Mercuri NB, North RA (1988) On the potassium conductance increase activated by $G A B A_{B}$ and dopamine $D_{2}$ receptors in rat substantia nigra neurones. $J$ Physiol (Lond) 401:437-453.

Lacey MG, Mercuri NB, North RA (1989) Two cell types in rat sub- 
stantia nigra zona compacta distinguished by membrane properties and the actions of dopamine and opioids. J Neurosci 9:1233-1241.

Llinas R, Greenfield SA, Jahnsen H (1984) Electrophysiology of pars compacta cells in the in vitro substantia nigra: a possible mechanism for dendritic release. Brain Res 294:127-132.

Lovinger DM, White G, Weight FF (1989) Ethanol inhibits NMDAactivated ion current in hippocampal neurons. Science 243:17211724.

Manev H, Costa E, Wroblewski JT, Guidotti A (1990) Abusive stimulation of excitatory amino acid receptors: a strategy to limit neurotoxicity. FASEB J 4:2789-2797.

Marsden CD (1990) Parkinson's disease. Lancet 335:948-952.

Mayer ML, Westbrook GL, Guthrie PB (1984) Voltage-dependent block by $\mathrm{Mg}^{2+}$ of NMDA responses in spinal cord neurons. Nature 309:261-263.

McKenna PJ (1987) Pathology, phenomenology and the dopamine hypothesis of schizophrenia. Br J Psychiatry 151:288-301.

Mercuri NB, Calabresi P, Bernardi G (1990) Effects of glycine on neurons in the rat substantia nigra zona compacta: in vitro electrophysiological study. Synapse 5:190-200.

Mereu G, Passino N, Carcangiu G, Gessa GL (1988) Electrophysiological evidences for the primary role of dopamine in the central effects of alcohol and other drugs of abuse. In: Neurodegenerative disorders (Nappi G, Hornykiewicz O, Agnoli A, Fariello RG, Clavazza A, eds), pp 287-301. New York: Raven.

Monaghan DT, Bridges RJ, Cotman CW (1989) The excitatory amino acid receptors: their classes, pharmacology, and distinct properties in the function of the central nervous system. Annu Rev Pharmacol Toxicol 29:365-402.

Nowak L, Bregestovsky P, Ascher P, Herbet A, Prochiantz A (1984) Magnesium gates glutamate-activated channels in mouse central neurons. Nature 307:462-465.

Sah P, Hestrin S, Nicoll RA (1989) Tonic activation of NMDA receptors by ambient glutamate enhances excitability of neurons. Science 246:815-818.

Scarnati E, Proia A, Campana E, Pacitti C (1986) A microiontophoretic study on the nature of putative synaptic neurotransmitter in the pedunculopontine-substantia nigra pars compacta excitatory pathway of the rat. Exp Brain Res 62:470-478.

Silva NL, Pechura CM, Barker JL (1990) Postnatal dopaminergic neurons exhibit five types of potassium conductances. J Neurophysiol 64:262-272.

Snyder SH (1973) Amphetamine psychosis: a model schizophrenia mediated by catecholamines. Am J Psychiatry 130:61-67.

Storm-Mathisen J, Ottersen OP (1989) Anatomy of putative glutamatergic neurons. In: Neurotransmitters and cortical function (Avoli M, Reader TA, Dykes RW, Gloor P, eds), pp 39-70. New York: Plenum.

Wallen P, Grillner S (1987) $N$-methyl-D-aspartate receptor-induced inherent oscillatory activity in neurons active during fictive locomotion in the lamprey. J Neurosci 7:2745-2755. 